Conclusion Illiteracy and poor socio-economic status leading to faulty feeding practices are the factors still predominant in developing countries which result in increased incidence of malnutrition in children. However, government-led programmes like ICDS through Anganwadis can help improving both education and nutritional status of mothers as well as children as evidenced by lower incidence of malnutrition in families attending Anganwadis regularly and utilizing nutrition and health care services.

\section{ACID AND NON ACID GASTROESOPHAGEAL REFLUX IN CRITICALLY ILL MECHANICALLY VENTILATED AND TUBE- FED INFANTS}

doi:10.1136/archdischild-2012-302724.1460

C Hallal, D Manica, VS Chaves, P Marostica, EA Trotta, PA Carvalho, FU Fontella, US Matte, SGS Barros, HAS Goldani. Hospital de Clinicas de Porto Alegre - Universidade Federal do Rio Grande do Sul, Porto Alegre, Brazil

Background and Aims Critically ill patients mechanically ventilated have high risk of gastroesophageal reflux (GER) and pulmonary aspiration. We aimed to evaluate the characteristics of acid and non acid GER in critically ill infants undergoing mechanical ventilation.

Patients and Methods Twelve infants undergoing mechanical ventilation suffering from severe bronchiolitis were enrolled. They were sedated, off any antiacid secretory medicines and on full enteral nutrition. They underwent MII-pH study by using equipment Sleuth-Sandhill Scientific, USA. Data were manually analyzed by using software BioVIEW Analysis version 5.6 (Sandhill Scientific). Parameters analyzed were: number of total episodes of GER (NGER); height of refluxate [proximal (PGER) or distal (DGER)]; reflux content [acid (AGER) or non acid (NAGER)]; and acid reflux index (ARI) - \% of time $\mathrm{pH}$ is under 4- considered altered when ARI is $>10 \%$. Data were analyzed by Wilcoxon test.

Results Overall median age was 3 months (range 1-12m), 9 males. Only two patients had ARI above 10\%. There were 362 GER episodes. Median NGER of each patient was 29.5(3-77). There was significant difference between PGER and DGER [23.5(7.2-36.2) vs 6.0(5.0-9.0), $\mathrm{p}=0.003]$ and between acid and non acid DGER [0.0 $(0.0-2.7)$ vs $6.0(2.5-7.7), p=0.036)$. There was no significant difference between acid and nonacid NGER and between acid and non acid PGER.

Conclusion Proximal GER was more significant than distal GER and there was no difference between acid and non acid content. This finding reinforces the risk of pulmonary aspiration of both acid and non acid reflux in infants undergoing mechanical ventilation.

\section{NUTRITION IN PEDIATRIC INTENSIVE CARE UNIT}

doi:10.1136/archdischild-2012-302724.1461

'A Violaki, ${ }^{2}$ S Stabouli, ${ }^{1} \mathrm{R}$ Dimitriadou, 'E Volakli, ' 'L Vogiagi, 'M Kotsiou, ${ }^{1} \mathrm{~K}$ Skoumis, ${ }^{1} \mathrm{M}$ Sdouga. 'Pediatric Intensive Care Unit; ${ }^{2}$ Pediatric Intensive Care, Hippokratio General Hospital, Thessaloníki, Greece

Nutritional support is a basic component of clinical management in the Pediatric Intensive Care Unit (PICU).

Aim The objective of this study is to evaluate the nutritional status of PICU patients, comparing the predicted energy expenditure (EE) by Harris-Benedict equation and the actually administered energy via enteral, parenteral or mixed nutrition.

Materials and Methods The files of 20 mechanically ventilated patients admitted to PICU, with length of stay $>5$ days, were studied retrospectively. Data collected included age, mean day of starting nutrition, route of feeding and mean day of reaching the highest caloric goal. At that day, energy predicted by Harris-Benedict equation was compared with the actually administered energy and the proportion of administered proteins, carbohydrates and fats as well as serum alboumin, glucose, $\mathrm{C}$ reactive protein and nitrogen balance were recorded.

Results Mean day of starting nutrition was $2.55 \pm 1.10$ and mean day of reaching the highest caloric goal was 7.06 \pm 2.54 . At that day, mean predicted EE was $49.5 \pm 26.46 \mathrm{Kcal} / \mathrm{kgr} / \mathrm{d}$, mean energy actually administered was $51.39 \pm 25.14 \mathrm{Kcal} / \mathrm{kgr} / \mathrm{d}$ and mean protein intake $1.13 \pm 0.34 \mathrm{gr} / \mathrm{kgr}$. Most children $(70 \%)$ received enteral nutrition and $62 \%$ were in negative nitrogen balance.

Conclusion Enteral feeding is the most preferable in PICU. Intolerance of feeding and various procedures were the main causes of delay reaching the caloric goal. Predicted and administered energy did not differed significantly. Despite the adequate caloric intake the nitrogen balance was mainly negative, due to catabolism and inadequate protein intake.

\section{THE EFFECT OF ORAL VITAMIN E ON RENAL ANEMIA IN CHRONIC HEMODIALYSED CHILDREN}

doi:10.1136/archdischild-2012-302724.1462

A Modarresi. Pediatrics, Mashhad University of Medical Sciences, Mashhad, Iran

Objectives Renal anemia is one of the most frequently observed complications in patients undergoing chronic hemodialysis. Reduced red blood cell survival due to oxidative damage is one of the causes of anemia in these patients. Vitamin $\mathrm{E}$ is a natural biological antioxidant, which protects cells from the effects of reactive oxygen metabolites and could be useful as a collateral therapy for anemia in these patients.

The Aim of the present study was to investigate the potential beneficial effect of vitamin E supplementation on renal anemia and to find out whether this improvement mechanism is attributable to the enhanced hematopoietic function or to prolonged RBC life.

Methods This case - control study included 15 stable children on chronic hemodialysis in Mashhad. All of children received subcutaneous erythropoietin $120 \mathrm{u} / \mathrm{kg} /$ week, oral folic acid $1 \mathrm{mg} /$ day and iron $2 \mathrm{mg} / \mathrm{kg} /$ day. Oral vitamin E $200 \mathrm{u} /$ day was prescribed to the cases only. Laboratory parameters determined at the beginning of the study were: Iron, Ferritin, Transferrin, TIBC, Hemoglobin, Hematocrit, Reticulocyte count and peripheral blood smear. $\mathrm{Hb}$ and Hct were checked every month during the study and were compared with earliers.

Results Perscription of oral vitamin E for 3 months resulted in significantly higher levels of $\mathrm{Hb}$ and $\mathrm{Hct}$ in the cases compared to those in the controls $(\mathrm{Hb}=11.4 \pm 1.7$ vs. $10.1 \pm 1.9$ and $\mathrm{Hct}=35.3 \pm 5$ vs. $31.3 \pm 6, \mathrm{P}<0.05)$.

Conclusion Antioxidant vitamin E supplementation improves renal anemia by decrease of oxidative stress and RBC life span in patients under hemodialysis.

\section{NUTRITIONAL SUPPORT IN PEDIATRIC INTENSIVE CARE UNIT OF UNIVERSITY HOSPITAL CENTRE “MOTHER THERESA", TIRANA, ALBANIA}

doi:10.1136/archdischild-2012-302724.1463

II Kito, ${ }^{2}$ A Simaku, 'E Kola, 'R Lluka, II Bakalli, 'E Gjyzeli, 'D Sala, 'A Vula, 'E Llazo, 'V Hajro, 'S Sallabanda. 'University Hospital Centre 'Mother Theresa'; 'Institute of Public Health, Tirana, Albania

Background and Aim Providing adequate caloric amount to critically ill children is challenging. The aim of the study is to describe the nutritional support of patients in Pediatric Intensive Care Unit and evaluate our current practice.

Material and Methods Prospective evaluation of the nutritional support of 126 critically ill children hospitalized for $\geq 48$ hours in PICU at University Hospital Centre over the period October 2011-March 2012. The amount of calories delivered 